\title{
O ESTADO DE DIREITO ECOLÓGICO COMO INSTRUMENTO DE CONCRETIZAÇÃO DE JUSTIÇA AMBIENTAL
}

\section{Carolina Medeiros Bahia* Melissa Ely Melo*}

Resumo: O presente artigo investiga a importância do Estado de Direito Ecológico, modelo de Estado que, comprometido com a sustentabilidade forte, respeita os direitos inerentes à natureza e passa a impor obrigações jurídicas vinculantes na preservação do meio ambiente, para o alcance da Justiça Ambiental. Para tanto, empregando o método indutivo, analisa o agravamento da crise ambiental e a transição para o Estado de Direito Ecológico; Faz uma reflexão acerca da noção de "Justiça"; Debate a Justiça Ambiental e suas facetas e conclui que este novo modelo de Estado fornece o alicerce legal indispensável para à materialização da Justiça Ambiental.

Palavras-chave: Crise Ambiental; Estado de Direito Ecológico; Obrigações Jurídicas Vinculantes; Justiça; Justiça Ambiental.

\section{THE RULE OF ECOLOGICAL LAW AS AN INSTRUMENT FOR IMPLEMENTING ENVIRONMENTAL JUSTICE}

Abstract: This article investigates the importance of the Rule of Ecological Law, a model of State that, committed to strong sustainability, respects the rights inherent to nature and now imposes binding legal obligations in the preservation of the environment, in order to achieve Environmental Justice. To do so, using the inductive method, analyzes the aggravation of the environmental crisis and the transition to the Rule of Ecological Law; Reflects on the notion of "Justice"; Debates the Environmental Justice and its facets and concludes that this new model of State provides the indispensable legal foundation for the materialization of Environmental Justice.

Keywords: Environmental Crisis; Rule of Ecological Law; Binding Legal Obligations; Justice; Environmental Justice.

\section{Introdução}

\footnotetext{
*Doutora em Direito pela Universidade Federal de Santa Catarina (UFSC). Professora Adjunto C, nível I, do Centro de Ciências Jurídicas da UFSC, atuando nos Cursos de Graduação, Mestrado Acadêmico e Mestrado Profissional. Membro do Grupo de Pesquisa Direito Ambiental na Sociedade de Risco (GPDA/UFSC-CNPq). Diretora do Instituto O Direito Por Um Planeta Verde. carolmbahia@hotmail.com

*Doutora em Direito pela Universidade Federal de Santa Catarina (UFSC), com estágio de doutoramento na Universidade de Alicante (Espanha) pelo PDSE da CAPES. Membro do GPDA/UFSC-CNPq. Professora em Cursos de Graduação e Pós-graduação Lato Sensu da UNIVALI. Pós-Doutorado na UFSC com bolsa do CNPq (PDJ - Processo n. 150114/2017-6). O trabalho foi realizado com auxílio financeiro do CNPq. melissaelymelo@hotmail.com
} 
A nova etapa da modernidade que, de acordo com Ulrich Beck (2002) é chamada de Sociedade de Risco, surge a partir da radicalização do processo de produção e do próprio sucesso da Sociedade Industrial, mas gera uma série de dificuldades para a ciência e para os juristas, uma vez que o instrumental técnico e as normas de definição criadas na etapa anterior são incapazes de conter ou controlar as novas ameaças. Assim, é marcada pelo surgimento de riscos de uma nova qualidade que, diversamente daqueles produzidos pela Sociedade Industrial, são caracterizados pela incerteza na sua produção causal e pela sua projeção no tempo e no espaço.

Para Beck (2002), as novas ameaças também não levam em conta as diferenças sociais, já que atravessam as trincheiras do luxo e da riqueza, sem atribuir a ricos ou pobres qualquer privilégio. Haveria, assim, uma espécie de efeito bumerangue, pois os riscos da modernização terminam por afetar mais cedo ou mais tarde aqueles que os produziram.

Além disso, a pressão exercida pelas sociedades humanas sobre os processos planetários, bem acima dos limites críticos, provocou a emergência de uma nova era geológica, denominada Antropoceno, cujas condições ambientais, conforme previsões de especialistas, serão catastróficas para a resiliência das sociedades humanas e economias.

Diante desse panorama alarmante, reacendem-se as discussões em torno da necessidade de se moldar um novo modelo de Estado, que apresentando uma maior sensibilidade ecológica e um compromisso com a sustentabilidade forte seja capaz de lidar com os novos desafios - o Estado de Direito Ecológico.

Por outro lado, a realidade dos fatos também faz questionar se a distribuição das mazelas ocorre, realmente, de maneira democrática, pois, do mesmo modo que existem segmentos que se beneficiam com a produção do risco, é certo que há outros que são afetados de uma maneira mais importante por essas ameaças. Tratam-se aqui das minorias e dos grupos vulneráveis da sociedade, grupos marginalizados, invisibilizados e esquecidos pelo Estado e que, por isso, além de não participarem e não serem levados em consideração nos processos de tomada das decisões ambientais, têm os seus direitos de cidadania frequentemente negados.

O presente artigo, partindo de pesquisa bibliográfica e documental e empregando o método indutivo, pretende lançar luz sobre a complexa questão que envolve a efetivação de 
um modelo de Estado que sendo, ao mesmo tempo ecológico, democrático e igualitário, sirva de alicerce normativo para a concretização da Justiça Ambiental em uma perspectiva ampla.

Para alcançar esse desiderato, analisar-se-á em seguida: o agravamento da crise ambiental e a transição do modelo de Estado de Direito Ambiental para o Estado de Direito Ecológico; uma breve reflexão acerca da noção de "Justiça" e as suas distintas abordagens; debate acerca da Justiça Ambiental e suas diversas facetas e o reconhecimento do Estado de Direito Ecológico como alicerce legal para a materialização dessa Justiça Ambiental.

\section{A crise ambiental e a insuficiência do Estado de Direito Ambiental}

O Estado de Direito pode ser compreendido como aquele que se submete às leis que edita, que estabelece limites para o poder político.

Uma análise histórica demonstra a existência de um nexo de interdependência genética e funcional entre o Estado de Direito e a garantia dos direitos fundamentais, pois, se por um lado, o Estado de Direito necessita assegurar os direitos fundamentais para ser considerado como tal, os direitos fundamentais dependem do Estado de Direito para a sua concretização.

Assim, também é possível classificar o Estado em Estado de Direito liberal ou social a depender da abrangência e do significado que nele se reserve aos direitos fundamentais, que podem ser restringidos à sua dimensão individual ou conjugados com a exigência de solidariedade.

A crise ambiental experimentada pela modernidade acarretou a emergência de uma nova dimensão de direitos fundamentais, que passou a impor ao Estado de Direito o desafio de introduzir dentre as suas funções prioritárias a proteção do meio ambiente.

Por isso, depois de a humanidade ter vivenciado formas de Estado liberal e de Estado de Bem Estar Social, com a respectiva positivação dos direitos de primeira e de segunda geração, apostou-se na consolidação do chamado Estado de Direito Ambiental, que seria, na visão de Ingo Sarlet e Tiago Fensterseifer (2011, p. 97), “[...] um Estado preocupado com as questões ambientais e com o objetivo de proteção do meio ambiente".

Segundo os autores, o Estado de Direito, na sua configuração tradicional, não foi capaz de fazer frente às ameaças da sociedade contemporânea, sobretudo, porque a esfera pública não se equipou adequadamente para o enfrentamento da nova escalada dos riscos e incertezas (SARLET; FENSTERSEIFER, 2011, p. 98). 
Neste quadro, caberia, então, ao Estado de Direito Ambiental, manter as conquistas dos demais modelos de Estado em termos de proteção da dignidade humana, agregando a elas uma dimensão ecológica, que garantiria “[...] a estabilização e prevenção do quadro de riscos e degradação ecológica" (SARLET; FENSTERSEIFER, 2011, p. 42).

Contudo, passados mais de quarenta anos da primeira Conferência das Nações Unidas para o Meio Ambiente, em Estocolmo, e do processo de esverdeamento das Constituições que se verificou em seguida, observa-se que, a despeito dos objetivos políticos adotados, dos instrumentos econômicos e legais estabelecidos e das mudanças de atitude e esforços feitos, os níveis de degradação do meio ambiente continuam a seguir uma tendência alarmante.

Esse quadro é ainda mais agravado quando se considera que a Humanidade enfrenta hoje uma nova etapa da Modernidade, denominada Sociedade de Risco, caracterizada pela emergência de riscos potencialmente globais, invisíveis, imperceptíveis pela ciência e que apresentam efeitos projetados no tempo e, por isso, são impassíveis de controle pelos instrumentos técnicos e jurídicos moldados até então e que o Planeta Terra, por conta das intervenções antropogênicas iniciadas a partir da Revolução Industrial, inaugurou uma nova era geológica, denominada Antropoceno.

Discorrendo sobre o tema, Kim e Bosselmann (2015, p. 195) destacam que enquanto o Holoceno, período de 11. 700 anos anteriores, foi marcado por um clima não usualmente estável, que permitiu o desenvolvimento e florescimento das civilizações, as condições do Antropoceno serão muito provavelmente catastróficas para a resiliência das economias e sociedades humanas (KIM; BOSSELMANN, 2015, p. 195).

A emergência do Antropoceno é produto da pressão que as sociedades humanas vêm exercendo sobre os processos do sistema terrestre, que terminam por ultrapassar os limites considerados críticos e, neste contexto, a manutenção das condições do Holoceno desponta como a melhor aposta para a sobrevivência humana (KIM; BOSSELMANN, 2015, p. 195).

Entretanto, para que esta meta seja alcançada, é indispensável introduzir a ideia de limites biofísicos planetários tanto na ordem internacional quanto na governança dos Estados e corporações (KIM; BOSSELMANN, 2015, p. 195).

Ao discutir as causas do fracasso estatal na tutela do meio ambiente, Kloepfer (2010, p. 41-42) observa que a política para o meio ambiente precedente não disponibilizou um instrumental suficientemente efetivo para a proteção ambiental, sendo necessário, então, 
traçar novos caminhos para a política ambiental e promover uma "virada ecológica". Já Bugge (2013, p.5) constata que a tendência de destruição continua crescente por conta dos valores dominantes de crescimento econômico e de consumo material que orientam a nossa civilização.

Por isso, para uma mudança no quadro atual, boa parte da doutrina reconhece a necessidade imperativa de se atribuir a prioridade mais elevada à proteção ambiental como um objetivo político, e limitar o crescimento econômico e o consumo no sentido tradicional, por meio da constituição de outro modelo de Estado - o Estado de Direito Ecológico.

Na opinião de Kloepfer (2010, p. 44), essa "virada ecológica" do Estado de Direito pressupõe a superação do princípio egocêntrico de proteção do meio ambiente, evoluindo-se para um quadro em que o reconhecimento de um dever de consideração ultrapasse o interesse próprio ou de pessoas que nos estão próximas, com a consequente garantia de direitos próprios à natureza.

Essa estratégia de atribuir um valor intrínseco para a natureza deve ser complementada pelo reconhecimento da existência de limites biofísicos planetários que condicionam a capacidade de resiliência do Planeta e a própria possibilidade de manutenção de um espaço ecológico seguro, para a sobrevivência tanto dos seres humanos quanto não-humanos.

Como explicam Kim e Bosselmann (2015, p. 195), o arcabouço dos limites planetários está fundamentado na teoria da resiliência, que considera a Terra como um sistema complexo e adaptativo, que, operando dentro de certos limites, apresenta a capacidade de absorver choques, mantendo as suas funções. Todavia, quando esses limites são ultrapassados, o sistema já não consegue preservar a sua identidade original, assumindo uma configuração diferente.

De fato, estudos científicos demonstram que as atividades humanas têm sobrecarregado o sistema terrestre e reduzido a sua capacidade de resiliência às perturbações. Segundo Kim e Bosselmann (2015, p. 196), quatro dos sete limites planetários, que podem ser quantificados a um nível global, já foram ultrapassados: as mudanças climáticas, a integridade da biosfera, a mudança do sistema terrestre e os fluxos biogeoquímicos. Outros limites encontram-se sob ameaça.

Para os autores, o arcabouço dos limites planetários pode ser empregado para traçar as fronteiras entre o Holoceno e o Antropoceno, assim como para delimitar o tipo e o nível de atividades humanas que poderão ser admitidas para manter os limites dos processos e 
subsistemas planetários (KIM; BOSSELMANN, 2015, p. 196). Além disso, a maior parte dos limites planetários pode ser aferida por meio do controle de variáveis como a quantidade de gás carbônico presente na atmosfera e as taxas de extinção de espécies (KIM; BOSSELMANN, 2015, p. 196).

A partir destas premissas, é possível visualizar que o Estado de Direito Ecológico passa a demandar do Poder Público e dos particulares a adoção de deveres jurídicos mais rigorosos para o controle destas variáveis e a consequente preservação da capacidade de resiliência do sistema terrestre.

Atribuindo a mais elevada prioridade aos valores ambientais, respeitando os direitos inerentes à natureza e impondo a todos os atores jurídicos obrigações de resultado, o Estado de Direito Ecológico teria, então, melhores condições para combater a devastação causada pela Sociedade de Risco, controlar as atividades que gerem riscos significativos para o meio ambiente e manter os processos biofísicos planetários mais próximos das condições do Holoceno. Porém, considerando que nosso meio ambiente já ultrapassou os limites que garantiriam o funcionamento pleno dos ciclos ecológicos em diversas localizações, o Estado Ecológico teria, num primeiro momento, a missão de desacelerar as mudanças do Antropoceno.

Para melhor compreender essas questões, entende-se necessário analisar as discussões em torno da noção de "Justiça" e "Justiça Ambiental" como fins últimos do Estado de Direito Ecológico.

\section{Breve análise das distintas abordagens da noção de "Justiça"}

Pode-se dizer que o ponto de partida para se discutir padrões de justiça na modernidade tem sido o contexto do sistema econômico capitalista, o qual vem se configurando como sistema social (para além de econômico), uma vez que a sua dinâmica não está limitada à produção de riquezas, mas voltado para a determinação de um "modo de vida cultural".

E, se por um lado, a ideia moderna de justiça é diretamente vinculada ao princípio da igualdade, por outro, o acúmulo de riquezas, motor do capitalismo, é alcançado por uma lógica que contraria este princípio. Assim, a consolidação do sistema (econômico) capitalista teve o "custo" da produção de injustiças sociais. E, portanto, a acumulação de riqueza foi 
desenvolvida conjuntamente com a produção de desigualdade material entre os indivíduos, condição para o desenvolvimento do capitalismo. Essa relação paradoxal tornou-se um dos principais pontos de preocupação para as sociedades modernas e continua sendo para as contemporâneas.

O processo de acumulação requer a centralização das formas de produção, gerando excedente natural de força de trabalho em benefício dos que detêm estes meios. Historicamente, a fórmula para desenvolver esse processo é a expropriação.

Esse excedente de força de trabalho impulsionou a produção e a possibilidade de geração de mais riqueza, passível de ser acumulada por poucos. Já a ciência moderna, baseada em uma racionalidade própria foi construída na direção da apropriação dos fenômenos naturais potencializando sua reprodução como mecanismo de aumento/incremento do sistema produtivo.

Tal sistema econômico, tendo por base a expropriação e, vinculado à ciência moderna, transformou-se no centro de boa parcela das relações concebidas na modernidade, surge aí a sua identificação como fundamento das problemáticas modernas sobre "justiça" (BAGGIO, 2008, p. 29).

O universo jurídico não ficou de fora deste processo, uma vez que os juristas ocidentais sustentaram, ao longo da modernidade, que ele é um agregado de componentes distintos regidos pelas leis naturais da razão individual. E com esse fundamento, a visão holística do mundo enquanto cosmos, da Terra enquanto um todo pertencente à humanidade, por sua vez uma abundante comunidade que poderia acessá-la, é substituída por um enfoque humanista no indivíduo e na razão humana, trazendo como resultado a visão legal mecanicista (CAPRA; MATTEI, 2015).

A partir disso, a propriedade privada, dominação individual sobre bens imóveis, é tomada como o conceito base do sistema jurídico preponderante, assim como o mecanismo chave para tornar possível o governo desse novo sistema que, por seu turno, foi representado pela noção de soberania estatal (CAPRA; MATTEI, 2015). Do século XVI ao século XIX a doutrina jurídica irá tratar de desfazer os laços de solidariedade que ligavam os seres humanos entre si por meio daquilo que partilhavam (OST, 2005, p. 58). Assim, as crescentes reivindicações sociais por Justiça Ambiental são caracterizadas pela constatação de que existe uma má distribuição dos bens e dos riscos ambientais nas sociedades contemporâneas, responsáveis por afetar e mesmo violar direitos das parcelas mais vulneráveis da população.

Revista de Direito Ambiental e Socioambientalismo | e-ISSN: 2525-9628 | Porto Alegre | v. 4 | n. 2 | p. 38 - 59 | Jul/Dez. 2018 
No que concerne à realidade brasileira, ainda que as formas de expropriação possam ter ocorrido de maneira bastante diversas da europeia, elas não deixaram de ocorrer (ou melhor, ainda ocorrem). Haja vista a dizimação das populações indígenas ocasionadas, no passado, em nome do processo de colonização e, no presente, em nome do capital ou como tem sido preferido, em nome do desenvolvimento. Exemplo muito emblemático e atual é o conhecido caso da Usina Hidrelétrica de Belo Monte.

Depois de oferecido este raciocínio, torna-se evidente que a análise teórica acerca da produção e reprodução de injustiças (de uma maneira geral) tenha sido norteada por um debate sobre a distribuição dos bens em sociedade.

Tendo em vista que a acumulação desses bens leva à percepção de que a desigualdade, concebida por esta perspectiva, afeta frontalmente a condição material de sobrevivência dos seres humanos, a conclusão é de que somente pode ser resolvida através da introdução de critérios distributivos que permitam criar condições mais igualitárias de relacionamento social.

Por isso, todos os debates teórico-jurídicos desenvolvidos pelas teorias da justiça, dominantes ao longo das últimas quatro décadas, salientam a perspectiva distributiva como objetivo de justiça a ser alcançada e controlada pelo Estado. (BAGGIO, 2008, p. 33)

O Estado Social, por sua vez, chama para si a responsabilidade de criar mecanismos redistributivos como garantia de melhora nas condições de vida em sociedade, estimulando a perspectiva da distribuição como um elemento indispensável dos debates acerca de justiça.

Por sua vez, a teoria de Rawls (2008), focada em uma concepção de justiça definida como uma distribuição de bens numa dada sociedade, bem como nos melhores princípios para distribuí-los, vem servindo de base tanto para definir, quanto para proceder a justiça.

No entanto, as discussões em torno das concepções de justiça se transformaram muito desde a publicação de "Uma Teoria da Justiça", de John Rawls. Assim, existem diversas propostas teóricas de ampliação do enfoque da noção de justiça para além dos aspectos distributivos. Tais perspectivas vêm sendo amplamente debatidas por inúmeros pensadores ao redor do mundo que, apesar de não negarem os problemas relativos à distribuição, advogam por uma abordagem dos processos responsáveis pela construção da inadequação da distribuição. 
Autores como Young (1990), Fraser (2007), Honneth (2003) argumentam que enquanto a justiça deve concernir às clássicas questões distributivas, também deve preocuparse com os processos que geram as más distribuições. Suas construções teóricas estão todas focadas na perspectiva de que o reconhecimento individual e social constitui elemento chave para a obtenção de justiça. Importa ressaltar que maior destaque é dado aos menos favorecidos em esquemas distributivos, do que propriamente aos elementos fisiológicos do reconhecimento. (SCHLOSBERG, 2009, p. 4)

Assim, ainda que a perspectiva da justiça distributiva continue sendo dominante, vem sendo cada vez mais contestada por outras abordagens de justiça. Os referidos autores Young (1990), Fraser (2007), Honneth (2003) percebem a ausência de reconhecimento nos âmbitos sociais e políticos como geradores de danos tanto aos indivíduos, quanto às suas comunidades.

A esses elementos, Sen (2011) e Nussbaum (2013) acrescentam o das capacidades, baseados em uma Teoria da Justiça focada nas capacidades necessárias para que os indivíduos tenham suas funções desenvolvidas de forma plena dentro de suas escolhas em termos de caminho de vida. A questão central para eles não é a distribuição dos bens e, sim, principalmente, o processo pelo qual esses bens são transformados em "florescimento" de indivíduos e comunidades.

Desta maneira, para eles a questão chave na compreensão da complexa noção de justiça, é saber em que medida a distribuição ou a ausência dela afeta a qualidade de vida dos sujeitos que buscam por justiça, assim como as suas "capacidades” para alcançá-la.

Trata-se de abordagem que persegue um significado ético para esta função e florescimento de capacidades nos indivíduos, grupos e comunidades. Advogam pela percepção de sua limitação como uma forma de injustiça e responsável pela geração de danos sociais. As denominadas "Teorias das Capacidades" examinam o que é preciso para transformar "bens primários", uma vez que estejam presentes, em uma "vida plenamente funcional” e o "que" é responsável pela interrupção desse processo.

Além disso, as "teorias da justiça" na contemporaneidade frequentemente adotam elementos processuais e participativos. Por exemplo, para Fraser (2007), a participação compõe um tripé, juntamente com a "distribuição" e o "reconhecimento".

No caso de Sen (2011) e Nussbaum (2013), a participação é uma capacidade política chave, requisito básico para que os indivíduos alcancem seu pleno funcionamento. Segundo 
Schlosberg (2009, p. 40), as teorias contemporâneas de justiça fazem referência a um standpoint, ponto de vista que é mais amplo do que simplesmente como as coisas são distribuídas. Este standpoint inclui a percepção teórica acerca do reconhecimento, da participação e do "funcionamento" das pessoas, referindo-se tanto a indivíduos, quanto a grupos.

Portanto, os autores mencionados apesar de admitirem a relevância das teorias distributivas da justiça, entendem que a justiça social não pode ser reduzida à mera distribuição, uma vez que o reconhecimento constitui elemento essencial a ser levado em consideração, além de temas ligados à representação e participação.

O próximo tópico tem como objetivo verificar de que forma essas questões impactaram (ou não) as discussões em torno da chamada "Justiça Ambiental".

\section{A configuração da Justiça Ambiental}

Destacou-se que os aspectos distributivos da noção de justiça ainda são considerados como um grande desafio na busca de igualdade material nas sociedades capitalistas e nem poderia ser diferente, uma vez que é evidente a necessidade de alcançar igualdade material pela introdução de instrumentos de distribuição de riqueza em sociedade. Embora seja importante reiterar o avanço das Teorias da Justiça para incluir outros elementos imprescindíveis para o empoderamento dos indivíduos, grupos sociais e comunidades.

A influência das "Teorias Distributivas da Justiça" também é dominante em matéria ambiental, ou seja, as discussões teóricas que tratam da Justiça Ambiental concebem a problemática sob a ótica de que é preciso criar mecanismos distributivos dos riscos e dos bens ambientais.

Schlosberg (2009), que analisou os discursos teóricos acerca da Justiça Ambiental afirma que os mesmos incorporam uma abordagem liberal de justiça, limitando-se a discussão de questões de cunho distributivo.

Assim, as crescentes reivindicações sociais por Justiça Ambiental são caracterizadas pela constatação de que existe uma má distribuição dos bens e dos riscos ambientais nas sociedades contemporâneas, responsáveis por afetar e mesmo violar direitos das parcelas mais vulneráveis da população. 
Desta forma, percebe-se que o ponto central da discussão sobre Justiça Ambiental tem sido a busca da superação das desigualdades impostas pelo processo de produção capitalista, evidenciadas pela grande concentração dos danos decorrentes da degradação da natureza em grupos sociais economicamente mais frágeis. E que esta superação poderia ser conduzida pela instituição de instrumentos de distribuição dos riscos e bens ambientais (BAGGIO, 2008, p. 16).

Tais reivindicações são relativamente recentes, pois somente a partir da década de 1980 se tornou evidente uma maneira de discriminação, produto da concentração dos danos decorrentes dos processos de degradação ambiental sobre certos grupos sociais. Este tratamento discriminatório relaciona a necessidade de respeito aos direitos humanos à questão da proteção do meio ambiente (BAGGIO, 2008, p. 16).

Não há como negar a existência de desigualdade social no processo de apropriação de riqueza e de distribuição dos riscos ambientais. De acordo com a análise feita por Albuquerque (2006, p. 22), acerca da "quimicalização" da sociedade moderna, ainda que os riscos possam ser globais, não são iguais para todos.

A evidência de que diversas indústrias químicas comercializam na América Latina produtos proibidos em seus países de origem já não é novidade. E, mesmo nos países desenvolvidos, a população mais carente é a mais exposta à contaminação química, por isso é possível afirmar, por exemplo, que nos Estados Unidos o “[...] mapa ecológico é também um mapa racial". As empresas mais poluidoras e os lixões mais contaminantes situam-se nos pontos de pobreza habitados por negros, índios e a população de origem latino-americana (ALBUQUERQUE, 2006, p. 30).

Os casos que ilustram esta distribuição desigual de riscos, danos ambientais e utilização de recursos naturais desigual não ficam restritos aos casos de contaminação. Os conflitos ambientais estão inseridos em um amplo leque de disputas incluindo os movimentos em defesa e reapropriação das matas e biodiversidade (tais como o movimento indiano Chipko, no Brasil o movimento dos seringueiros e o processo de consolidação de comunidades negras da Colômbia); também as demandas por compensação por danos ambientais (como derramamento de petróleo e desmatamento); o movimento que resiste ao neoliberalismo e aos Tratados de Livre Comércio; disputas entre a preservação ambiental e a comercialização de recursos, bens e serviços ambientais; dissensos acerca dos mecanismos econômico-jurídicos e os direitos de apropriação da natureza (tais como os direitos de 
propriedade intelectual e direitos dos agricultores e populações indígenas) (LEFF, 2006, p. 461).

O que importa denotar em todos estes casos é a nítida incompatibilidade existente entre a preservação do equilíbrio ecológico e os processos produtivos do capitalismo. Diante deste cenário repleto de ambiguidades, complexidades e ideologias, acredita-se ser essencial refletir acerca do que exatamente se entende pelo "Justiça" da "Justiça Ambiental?" O que os ambientalistas, os movimentos sociais e mesmo seus teóricos entendem quando fazem uso do termo.

O conceito de Justiça Ambiental vem sendo estudado e debatido ao longo das últimas décadas por ativistas e movimentos sociais não apenas nos EUA, onde primeiro surgiram, como também globalmente. Entretanto, para Schlosberg (2009, p. 2), por mais que tenha havido inúmeras discussões em torno do tema, existem pelo menos dois gaps a ser transpostos.

O primeiro deles é que, muito embora, a teoria política acerca da "justiça" tenha avançado, conforme visto no primeiro tópico anterior, suas inovações apenas raramente foram aplicadas pelos movimentos de Justiça Ambiental.

De acordo com o que foi evidenciado ao longo do tópico anterior, a Teoria da Justiça de Jonh Rawls, baseada em uma concepção de justiça definida como distribuição de bens em certa sociedade, bem como nos princípios corretos para distribuí-los, vem servindo de parâmetro tanto para definir, quanto para proceder a justiça. E esta realidade, como já afirmado, não se difere quando se tem como enfoque a Justiça Ambiental.

Apesar dos muitos desenvolvimentos presentes nas teorias que versam acerca da justiça em termos de elementos de reconhecimento, participação e capacidades, em termos teóricos, muito pouco tem sido endereçado aos movimentos que tratam da Justiça Ambiental. A grande maioria das discussões acerca dela refere-se à "má distribuição", isto é, ao fato de que "comunidades pobres", "povos indígenas" e "comunidades étnico-raciais" possuam acesso a menos bens ambientais, serem expostas a "maior grau de degradação ambiental", além de menor "proteção ambiental".

Para Schlosberg (2009, p. 4) o problema não está centralizado no fato de as teorias distributivas poderem ou não poderem ser aplicadas para a Justiça Ambiental e, sim, de que as Teorias da Justiça tenham desenvolvido uma série de modos de conceber os processos que 
geram justiças e injustiças e que, no entanto, esses desenvolvimentos raramente apareceram na literatura da Justiça Ambiental.

Reiterando, de um modo geral, o conceito de "justiça" e aqueles que vêm buscando compreender os movimentos que buscam por ela, têm enfatizado a importância de seus elementos processuais e participativos. Outros tantos, têm se focado em questões de reconhecimento, examinando as barreiras culturais e raciais para que indivíduos e grupos sociais encontrem justa distribuição (SCHLOSBERG, 2009, p. 5).

Todavia, não é possível afirmar que houve aprofundamento ou verdadeira compreensão teórica no que diz respeito ao que buscam os movimentos que se organizam em torno da Justiça Ambiental, suas distintas concepções e discursos acerca da "justiça".

Em sentido completamente inverso, de acordo com Schlosberg (2009, p. 5), no que diz respeito aos discursos encontrados na prática dos movimentos de Justiça Ambiental, também analisados por ele, é possível observar, claramente, que fazem uso de ampla variedade de concepções de justiça, podendo ser identificados argumentos distributivos, de reconhecimento, participação e capacidades.

Assim, os movimentos pela Justiça Ambiental fornecem amplas evidências de que todas estas distintas concepções de justiça são utilizadas na prática e que, na verdade, o entendimento da forma como os movimentos definem "justiça” da Justiça Ambiental devem incluir todos esses elementos (SCHLOSBERG, 2009, p. 5).

Nem surpreende o fato de existir tamanha diversidade de definições dentro dos grupos e movimentos que se organizam ao redor da concepção de Justiça Ambiental. Schlosberg $(2009$, p. 6) chega a afirmar que os movimentos sociais adicionam mais ao discurso de justiça do que boa parte dessas teorias. Segundo ele, há dois principais pontos para os quais os teóricos da justiça devem prestar mais atenção. Por primeiro que, conforme já verificado, frequentemente, os movimentos sociais fazem uso de múltiplos conceitos de justiça, de maneira simultânea. Por sua vez, também aceitam tanto a ambiguidade, quanto a pluralidade que surgem quando se adotam discursos tão heterogêneos.

Segundo, e muito importante, esses movimentos aplicam concepções de justiça não apenas para indivíduos, mas para grupos e comunidades. Schlosberg $(2009$, p. 6) afirma que os movimentos não percebem como um problema o fato de ultrapassarem o consenso (praticamente unânime) dos teóricos da justiça, para quem as definições de justiça aplicam-se apenas para os indivíduos (vistos isoladamente). 
Os movimentos por Justiça Ambiental exploram, definem, representam e demandam por justiça, distribuição justa, reconhecimento, capacidades e funcionamento para as comunidades e indivíduos. Pode-se dizer que esses movimentos são geralmente amplos, plurais e inclusivos, da mesma forma, suas definições e discursos de justiça vão desde aqueles baseados em reclamações distributivas individuais àquelas baseadas na sobrevivência de funcionamento da comunidade (SCHLOSBERG, 2009, p. 5).

Para o autor, esse distanciamento entre as Teorias da Justiça e os movimentos que buscam por Justiça Ambiental também faz parte desse mencionado primeiro gap, imprescindível de ser transposto. O autor traz grande contribuição no sentido de "usar" as "Teorias da Justiça" para "explorar" os movimentos sociais e, inversamente, esses últimos para expandir as primeiras. Trouxe, assim, evidências empíricas da relevância desses movimentos para o desenvolvimento das "Teorias da Justiça". Por outro lado, também ofereceu aos ativistas e seus movimentos uma visão teórica acerca das posições e demandas que eles expressam.

Além dessas questões em torno do que se concebe pela noção de "Justiça", faz-se necessário refletir acerca do "Ambiental". Nesse sentido, a discussão acerca da Justiça Ambiental como demanda social revela um cenário bastante complexo, que envolve não só o tema da "justiça", mas o da proteção da natureza. O primeiro ponto da problemática está presente na constatação de que as discussões acerca da proteção do meio ambiente e de respeito aos direitos humanos estão inseridos no contexto da crise ambiental, posta no campo de tensão da modernidade (BAGGIO, 2008, p. 16).

Assim, no plano filosófico, segundo Taylor (1997), de um lado a defesa da "razão moderna" estabelece uma relação utilitarista com os elementos da natureza e, de outro, identificada pelo autor como a concepção da natureza como uma fonte moral, suscita a busca de elementos da originalidade humana na natureza, concebendo um conjunto de valores que indiquem o que é igualmente bom para todas as formas de vida.

No mesmo sentido é a análise de Ost (1995), para quem de um lado concebe-se a natureza como objeto, e por outro, como sujeito de direitos, sem ser mais capaz de distinguir nem os vínculos nem os limites entre os seres humanos e esta "natureza".

Por isso, ainda que a problemática ambiental gere um aparente consenso sobre a necessidade da proteção e preservação do meio ambiente, na "realidade empírica" das 
sociedades contemporâneas este consenso está totalmente desencontrado, inclusive encontrando-se a situação oposta, a disputa no que concerne à concepção de natureza situada no centro desse conflito.

Tendo em vista este pressuposto conceitual, não se consegue classificar as demandas por Justiça Ambiental em nenhuma das duas distintas perspectivas presentes na tensão moderna, pois se deve considerar que o pressuposto destas demandas é a denúncia da credibilidade conferida à tecnologia como vertente principal criadora de discriminações à parte da população menos favorecida economicamente e que suporta os custos ambientais para a manutenção da produção e consumo nos padrões atuais (BAGGIO, 2008, p. 17).

A partir deste ponto de vista, a crise ambiental, mencionada no primeiro tópico do artigo e tantas vezes denunciada por aqueles que lutam por Justiça Ambiental, atinge frontalmente o mito do desenvolvimento (reduzido a mero crescimento econômico); Põe em dúvida a ciência, com a derrubada dos paradigmas tradicionais que têm como base o pensamento especializado e fragmentado; Alcança as variadas sociedades, cada vez mais desiguais e questiona os valores que norteiam a sociedade capitalista: o consumo e a visão antropocêntrica de mundo, que reduzem a natureza à mera matéria.

Além disso, a crise ambiental se apresenta como uma questão de poder, uma vez que deflagra as desigualdades sociais, pois poucos são responsáveis pela exploração dos recursos naturais em benefício próprio e afastam (temporal e espacialmente) as consequências danosas de suas ações. Assim, essas desigualdades impõem aos grupos mais desfavorecidos o sofrimento (de maneira mais imediata e próxima) das sequelas deste modelo de desenvolvimento em nada sustentável.

Evidencia-se que em face dos mais pobres, bem como dos grupos étnicos desprovidos de poder se apresenta, de forma desproporcional, a grande parte dos riscos ambientais socialmente construídos, tanto ao longo da extração dos recursos naturais, quanto na disposição dos dejetos no ambiente (ACSELRAD, 2009, p. 12).

Para agravar a situação, a debilidade estrutural destes grupos faz com que sejam muitas as barreiras para que mudanças neste modelo socioeconômico sejam ocasionadas, no sentido de que as externalidades ambientais sejam distribuídas equitativamente, ou mesmo, eliminadas.

E, ainda que, a discussão sobre a democratização da participação nos processos de tomadas de decisão institucionalizados tenha sofrido razoável incremento sob a égide da 
lógica distributiva, o que segue podendo ser questionado é em que medida esta base teórica é satisfatória para a compreensão do emergente "fenômeno" da Justiça Ambiental.

Retoma-se o questionamento feito no início deste tópico do artigo, seria a resposta distributiva capaz de abranger todos os mecanismos de produção de injustiças no que concerne às relações existentes entre os seres humanos e a natureza? Segundo a tese proposta por Baggio (2018, p. 18) e, reiterada pelos demais autores já referenciados, a hipótese da justiça distributiva reduziria a complexidade das relações estabelecidas em sociedade, uma vez que, termina ignorando muitos elementos importantes para a compreensão da geração de injustiças, reduzindo o quadro de identificação dos processos de desrespeito social.

$\mathrm{Na}$ tentativa de compreender as complexidades presentes nestas relações que, conforme visto, envolvem temas distributivos, de reconhecimento, capacidades e participação, Acselrad (2010, p. 98) propõe o esforço de se efetuar a passagem da noção de risco à de vulnerabilidade, alegando a necessidade de melhor articular as condições que tornam certos sujeitos mais suscetíveis a agravos. Assim, vulnerabilidade é noção relativa, normalmente associada à exposição aos riscos, designando pessoas, lugares, infraestruturas ou ecossistemas mais ou menos suscetíveis a algum agravo.

Por isso, se a vulnerabilidade é decorrente de uma relação estabelecida historicamente entre distintos segmentos sociais, somente será possível eliminá-la se as causas das privações vivenciadas por estas pessoas ou grupos sociais forem ultrapassadas, ocorrendo uma mudança nas relações mantidas com o espaço social no qual estão inseridos.

Desta forma, se a vulnerabilidade se constitui como uma relação, não como uma carência, a oferta compensatória de bens não pode enfrentá-la efetivamente. Para a captação da dimensão social da vulnerabilização, além da mensuração dos grupos de indivíduos considerados nesta situação, é preciso caracterizar os processos de vulnerabilização relativa, composta por elementos culturais e políticos (ACSELRAD, 2010, p. 101-102).

Segundo Baggio (2008, p. 17), o desafio fundamental que a discussão sobre Justiça Ambiental propõe é a superação dos problemas que ligam justiça social e proteção ambiental de forma que o processo de integração social se realize por meio do aprofundamento das relações democráticas. Para isso é fundamental que o sistema de garantias de direitos seja poupado, evitando a geração de risco permanente no processo de legitimação do Estado 
Democrático de Direito, que ocorrerá caso a realização das autonomias pública e privada dos sujeitos seja abalada.

A seguir busca-se a conexão das questões relativas às demandas por Justiça Ambiental e a necessidade de (re)construção de um novo de Estado, o Estado de Direito Ecológico, haja vista o agravamento da referida crise ambiental e da insuficiência do Estado de Direito Ambiental para controlá-la.

\section{Em busca do Estado de Direito Ecológico para a materialização de Justiça Ambiental}

Nas últimas décadas presenciou-se a transformação do mundo em uma realidade globalizada. Foram desenvolvidas facilidades, como a possibilidade de contato com culturas diversas, seja de forma presencial, seja pela rede mundial de computadores, pelo menos para a parcela da população que tem acesso aos novos meios de transporte e de comunicação.

No entanto, esta alteração também representou uma mudança na gravidade das externalidades negativas que começam a ser produzidas. Grande condutor desses impactos é o mercado, que passou a desempenhar papel de protagonista neste "novo mundo", especialmente tendo em vista a ausência de controle sobre ele.

Com o processo de globalização, apesar da emergência e estreitamento das redes de conexões (ambientais, sociais e econômicas) há um aprofundamento das distâncias em escala mundial, ou seja, o mundo é apenas parcialmente globalizado, em especial no que diz respeito aos benefícios oriundos deste. O que leva Keohane (2002) a entender que a governança deste processo não é feita de maneira global, uma vez que os seus distintos atores possuem papéis muito diferenciados em termos de poder na governança da globalização.

Assim, não há uma estrutura de poder institucionalmente bem definida para estabelecer regras nas disputas políticas e econômicas dentro do processo de globalização, tampouco um procedimento formal para as tomadas de decisão. Há um conjunto complexo e imbricado de redes de influências e instituições responsáveis por criar e difundir uma "ideologia econômica comum", assim realizando uma "função de governança global", inserindo efeitos consensuais transnacionais nos processos de tomada de decisão em nível nacional (GÓMEZ, 2000, p. 34-35).

Diante deste cenário, em nada favorável à proteção da natureza e de desempoderamento daqueles que lutam pelos direitos humanos, ambientais e ecológicos, bem 
como de diminuição do poder dos Estados Nações, em especial dos que possuem menor poder econômico dentro do contexto global, assevera-se a urgência de postular pelo fortalecimento do Estado. Mas não qualquer modelo de Estado e, sim, um Estado de Direito Ecológico, que sirva de alicerce legal para os ideais de Justiça Ambiental.

Como tentativa de fazer frente a esta situação, buscando maior proteção social, ambiental e ecológica, na Reunião da Comissão Mundial de Direito Ambiental (IUCN), ocorrida em abril de 2016, no Rio de Janeiro, os maiores pesquisadores da área debateram os fundamentos que devem lastrear a construção desse Estado ideal, concluindo que o Estado de Direito Ecológico deveria ser entendido como um conjunto de direitos e deveres processuais e substantivos que incorpora os princípios do desenvolvimento ecologicamente sustentável no Estado de Direito.

Esse encontro deu origem à Declaração Mundial do Estado de Direito Ecológico, que se assentou, dentre outras premissas, nas ideias de que o fortalecimento do Estado de Direito é fundamental para proteger os valores ambientais, sociais e culturais e para alcançar o desenvolvimento ecologicamente sustentável e de que, sem o Estado de Direito, não há Direito Ecológico e a aplicação dos direitos e obrigações legais, a governança ambiental, a conservação e a proteção podem ser arbitrárias, subjetivas e imprevisíveis.

A Declaração reconhece ainda que a construção de um Estado de Direito Ecológico e a presença de instituições fortes são essenciais para responder às pressões ambientais crescentes que ameaçam a integridade ecológica da Terra, de forma a respeitar os direitos fundamentais e os princípios da justiça, seja ela social, ambiental ou ecológica.

E, por tudo isso, conclui que o Estado de Direito Ecológico deve, servir de base jurídica para promover a ética ambiental e alcançar a Justiça Ambiental, a integridade ecológica global e um futuro sustentável para todos, inclusive para as gerações futuras, a nível local, nacional, subnacional, regional e internacional.

A concretização da Justiça Ambiental por este novo modelo de Estado passa necessariamente por uma releitura dos direitos humanos sob uma perspectiva ecológica e pela garantia dos chamados direitos ambientais procedimentais.

Sem dúvidas, um passo fundamental para a concretização do Estado de Direito Ecológico e a consequente realização da Justiça Ambiental é a adoção, tal como proposto por Bosselmann (2008), de uma abordagem de direitos humanos não baseada numa ética 
antropocêntrica, que considere que a natureza apresenta um valor intrínseco e que o homem tem obrigações com a natureza.

Nesta linha, deve-se reconhecer a existência de direitos ambientais procedimentais, que, vinculados à democracia e à participação, devem garantir a transparência, a responsabilização e a participação nos procedimentos decisórios, possibilitando um envolvimento do público nas decisões ambientais (BOSSELMANN, 2008). Além disso, é de todo conveniente a afirmação do direito a um meio ambiente saudável como um direito humano autônomo, mas considerado como pré-condição para a realização de todos os demais direitos humanos.

Esse reconhecimento ainda deve ser complementando com a previsão de deveres ambientais, que obriguem o Estado a criar leis, decretos e a desenvolver políticas públicas claras, efetivas e rigorosas, voltadas à proteção do meio ambiente e à prevenção e precaução de danos ambientais e a prever mecanismos que assegurem o cumprimento desta legislação, incluindo a responsabilização tanto na esfera cível quanto administrativa e penal.

As reflexões de Schlosberg (2009, p. 7) são bastante úteis para a construção teórica que aqui se pretende no sentido de fazer referência ao trabalho atribuído à Rachel Carson (2010) para melhor compreender a importância da reunião das preocupações ambientais que não haviam se encontrado até aquele momento, ou seja, do mundo humano e os animais que também nele habitam, além da preocupação com a saúde humana em face dos impactos industriais em indivíduos, suas comunidades e ecossistemas. Seu discurso acabou por inspirar um movimento ambientalista mais plural, estabelecendo conexões entre temas diversos. É neste viés que ele propõe a expansão da concepção de meio ambiente para uma noção mais inclusiva.

O aporte feito na obra de Schlosberg (2009) tem como objetivo expandir o discurso da justiça para legitimar o uso de uma variedade de ferramentas e noções que se aplicam a vários casos encontrados no mundo globalizado contemporâneo. Questões ligadas a desigualdade, reconhecimento, participação e a questão mais ampla, em torno das capacidades e funcionamentos de indivíduos e comunidades (humanas e não humanas) são passíveis de união em torno de um discurso abrangente e inclusivo, capaz de fortalecer o poder tanto explicativo, quanto mobilizador dos movimentos que usam a linguagem de Justiça Ambiental.

A nossa proposta é, assim, conforme visto, pensar em um novo modelo de Estado que, dentro de um quadro de Estado Democrático de Direito, ultrapasse o Estado de Direito 
Ambiental, servindo de base legal para a realização de Justiça Ambiental em um sentido amplo.

\section{Considerações Finais}

O presente artigo teve como escopo analisar o Estado de Direito Ecológico enquanto alicerce legal para a materialização de Justiça Ambiental em uma perspectiva abrangente. Para tanto, analisou-se algumas questões relacionadas à crise ambiental e a insuficiência do Estado de Direito Ambiental para dar conta dos desafios por ela propostos.

Posteriormente, buscou-se uma aproximação das demandas por "justiça" e suas distintas abordagens teóricas. Identificou-se, a partir do referencial teórico estudado que, apesar da relevância das Teorias Distributivas da Justiça, a justiça social não pode reduzir-se à distribuição, tendo em vista que o reconhecimento é elemento essencial a ser considerado, além de temas ligados à representação e participação.

Já em um segundo tópico, verificou-se que a influência das "Teorias Distributivas da Justiça" também é dominante em matéria ambiental, ou seja, as discussões teóricas que tratam da Justiça Ambiental concebem a problemática sob a ótica de que é preciso criar mecanismos distributivos dos riscos e dos bens ambientais, uma vez que os mesmos afetam e violam direitos das parcelas mais vulneráveis da população. Ainda que os movimentos que lutam por Justiça Ambiental permitam evidenciar que as distintas concepções de justiça são utilizadas na prática.

Por sua vez, o desafio fundamental que a discussão sobre Justiça Ambiental propõe é a superação dos problemas que ligam justiça social e proteção ambiental de forma que o processo de integração social se realize por meio do aprofundamento das relações democráticas.

A partir da evidência de um cenário desfavorável à proteção da natureza e de desempoderamento daqueles que lutam pelos direitos humanos, ambientais e ecológicos, bem como de diminuição do poder dos Estados Nações, especialmente daqueles que detém menor poder econômico dentro do contexto global, postulou-se pelo fortalecimento do Estado. Mas não qualquer modelo de Estado e, sim, um Estado de Direito Ecológico, que sirva de alicerce legal para os ideais de Justiça Ambiental amplamente considerada, nos moldes concebidos 
pela Declaração Mundial do Estado de Direito Ecológico, haja vista o agravamento da crise ambiental e da insuficiência do Estado de Direito Ambiental para controlá-la.

\section{Referências}

ACSELRAD, Henri. Vulnerabilidade ambiental, processos e relações. In: FERREIRA, Heline Sivini et al (Orgs.). Estado de Direito Ambiental: Tendências. 2. ed. Rio de Janeiro: Forense Universitária, 2010. p. 95-103

ACSELRAD, Henri; MELLO, Cecília Campello do A.; BEZERRA, Gustavo das Neves. O que é justiça ambiental. Rio de Janeiro: Garamond, 2009.

ALBUQUERQUE, Letícia. Poluentes Orgânicos Persistentes: uma análise da Convenção de Estocolmo. Curitiba: Juruá, 2006.

BAGGIO, Roberta Camineiro. Justiça Ambiental entre redistribuição e reconhecimento: a necessária democratização da proteção da natureza. 2008. Tese (Doutorado em Direito), Universidade Federal de Santa Catarina, Florianópolis, 2008.

BECK, Ulrich. La sociedad del riesgo global. Madrid: Siglo Veintiuno de España Editores S.A., 2002.

BOSSELMANN, K. Direitos humanos, ambiente e sustentabilidade. Publicado por: URL persistente: DOI: Accessed: URI : http://hdl.handle.net/10316.2/8821. CEDOUA, v. 21, p. 1$11,2008$.

BUGGE, Hans Christian. Twelve fundamental challenges in environmental law: an introduction to the concept of rule of law for nature. In: Christina Voigt (Ed.). Rule of Law for Nature: new dimensions and ideas in environmental law. New York: Cambridge University Press, 2013.

CAPRA, Fritjof; MATTEI, Ugo. The ecology of law: toward a legal system in tune with nature and community. Oakland, CA: Barret-Koheler Publishers, 2015.

CARSON, Rachel. Primavera silenciosa. Tradução de Claudia Sant'Anna Martins São Paulo: Gaia, 2010.

FRASER, Nancy. Reconhecimento sem ética? Revista Lua Nova, São Paulo, n. 70, p. 101138, 2007.

GÓMEZ, José María. Política e democracia em tempos de globalização. Petrópolis: Vozes, 2000 .

HONNETH, Axel. Luta por reconhecimento: a gramática moral dos conflitos sociais. São Paulo: Editora 34, 2003.

KEOHANE, Robert Owen. Power and governance in a partially globalized world. London, New York: Routledge, 2002.

KIM, R. E.; BOSSELMANN, K. International environmental law in the anthropocene: Towards a purposive system of multilateral environmental agreements. Transnational

Revista de Direito Ambiental e Socioambientalismo | e-ISSN: 2525-9628 | Porto Alegre | v. 4 | n. 2 | p. $38-59$ | Jul/Dez. 2018 
Environmental Law, v. 2, n. 2, p. 285-309, 2013.

KIM, Rakhyum; BOSSELMANN, Klaus. Operationalizing Sustentainable Development: Ecological Integrity as a Grundnorm of International Law. Review of European Community \& International Environmental Law, 24(2) 2015.

KLOEPFER, Michael. A caminho do Estado Ambiental? A transformação do sistema político e econômico da República Federal de Alemanha através da proteção ambiental especialmente desde a perspectiva da ciência jurídica. In: SARLET, Ingo. Estado Socioambiental e direitos fundamentais. Porto Alegre: Livraria do Advogado, 2010.

LEFF, Enrique. Racionalidade ambiental: a reapropriação social da natureza. Tradução de Luis Carlos Cabral. Rio de Janeiro: Civilização Brasileira, 2006.

NUSSBAUM, Martha C. Fronteiras da Justiça: deficiência, nacionalidade, pertencimento à espécie. São Paulo: WMF Martins Fontes, 2013.

OST, François. A natureza à margem da lei: a ecologia à prova do direito. Lisboa: Instituto Piaget, 1995.

RAWLS, John. Uma teoria da justiça. 3. ed. Tradução de Almiro Pisetta e Lenita M.R. Esteves. São Paulo: Martins Fontes, 2008.

SARLET, Ingo; FENSTERSEIFER, Tiago. Direito Constitucional Ambiental: estudos sobre a Constituição, os Direitos Fundamentais e a proteção do ambiente. São Paulo: Revista dos Tribunais, 2011.

SCHLOSBERG, David. Defining Environmental Justice: theories, movements and nature.New York: Oxford University Press, 2009.

SEN, Amartya. A ideia de justiça. São Paulo: Companhia das Letras, 2011.

TAYLOR, Charles. As fontes do self: a construção da identidade moderna. Tradução de Adail Ubirajara Sobral e Dinah de Abreu Azevedo. São Paulo: Loyola, 1997.

YOUNG, Iris Marion. Justice and the politics of difference. Princeton: Princeton University, 1990. 